\title{
Global Imbalances Revisited: The Transfer Problem and Transport Costs in Monopolistic Competition*
}

\author{
Paolo Epifani ${ }^{\dagger}$ \\ Gino Gancia ${ }^{\ddagger}$ \\ University of Nottingham \\ CREI, Barcelona GSE and CEPR
}

December 2015

\begin{abstract}
We study the welfare effects of trade imbalances in a two-sector model of monopolistic competition. As in perfect competition, a trade surplus involves an income transfer to the deficit country and possibly a terms-of-trade deterioration. Unlike the conventional wisdom, however, trade imbalances do not impose any double burden on surplus countries. This is because of a production-delocation effect, which leads to a reduction in the local price index. In the presence of intermediate goods, new results arise: A trade surplus may lead to an appreciation of the exchange rate, to a terms-of-trade improvement and to a welfare increase under standard parameter configurations. In addition, policies that stabilize the exchange rate can make the balanced-trade equilibrium unstable. These results can explain why the manufacturing sector may agglomerate in countries that resist the real appreciation of their currency and suggest that a fixed exchange rate and nominal rigidities may generate short-run instability.
\end{abstract}

JEL Classification: F1.

Keywords: Trade Imbalances; Trade Costs; Monopolistic Competition; Intermediate Goods.

\footnotetext{
${ }^{*}$ We thank seminar participants at various venues for comments. We acknowledge financial support from the Barcelona GSE and the Ministerio de Ciencia e Innovación (ECO2014-59805-P).

${ }^{\dagger}$ University of Nottingham, U.K. and Ningbo China, 199 Taikang East Road, 315100 Ningbo, P. R. China. E-mail: Paolo.Epifani@nottingham.edu.cn.

${ }^{\ddagger}$ CREI, Barcelona GSE and CEPR. Ramon Trias Fargas, 25-27, 08005, Barcelona, SPAIN. E-mail: ggancia@crei.cat
} 


\section{INTRODUCTION}

Trade imbalances are a key feature of the latest wave of globalization. Their study attracted renewed attention in recent years, when these reached alarming levels in major countries. For instance, in 2007 the United States ran a current account deficit of $6 \%$ of its GDP and China a surplus of nearly 10\%. Although the Great Recession and the subsequent collapse of international trade were also accompanied by a significant correction, global imbalances are not just a remnant of the past. As Figure 1 shows, in 2013 the current account imbalances of the United States and China stabilized around $2 \%$ of their respective GDP, but the surplus of Germany remained steadily above $6 \%$. Moreover, until very recently current account deficits remained large in peripheral European countries (Greece in Figure 1 is an example).

Despite their prevalence, the welfare implications of these imbalances are not fully understood, because trade models typically focus on the assumption of balanced trade, while models of international finance often focus on inter-temporal rather intra-temporal trade. This prevents the theory from shedding light on some recurrently debated issues about the complex interaction between real and financial variables. For instance, China's integration into the world economy was accompanied by large and growing trade surpluses. Did this type of trade opening harm or benefit China and its main trade partners? Similarly, it is widely believed that the creation of the Euro area, and the induced rigidities in the nominal exchange rates, helped Germany to accumulate huge trade surpluses. Did this help or undermine the process of European economic integration? More in general, what are the real effects of the international transfers that are so frequent in financially integrated areas such as the eurozone?

Trade theory does provide the tools for answering these questions. However, the dominant approach in the literature on trade imbalances builds on the assumptions of perfectly competitive markets and constant returns to scale. This approach, whose intellectual history dates back to the debate between Ohlin and Keynes on the effects of international transfers, was formalized by Samuelson (1954) and Dornbusch, Fisher and Samuelson (1977), and recently revived by Dekle, Eaton and Kortum (2007, 2008). Its main lesson is that a trade surplus is unambiguously welfare reducing because it involves a double burden, i.e., an income transfer to the trading partner and a terms-of-trade deterioration. This conclusion is however at odds with the common wisdom surrounding policy debates. For instance, if trade imbalances always benefit deficit countries at the expense of surplus countries, how is it that the U.S. administration often complains that China's large bilateral trade surpluses are harming the U.S. economy? And how is it that China accumulated such large surpluses and tried to postpone as much as possible the rebalanc- 


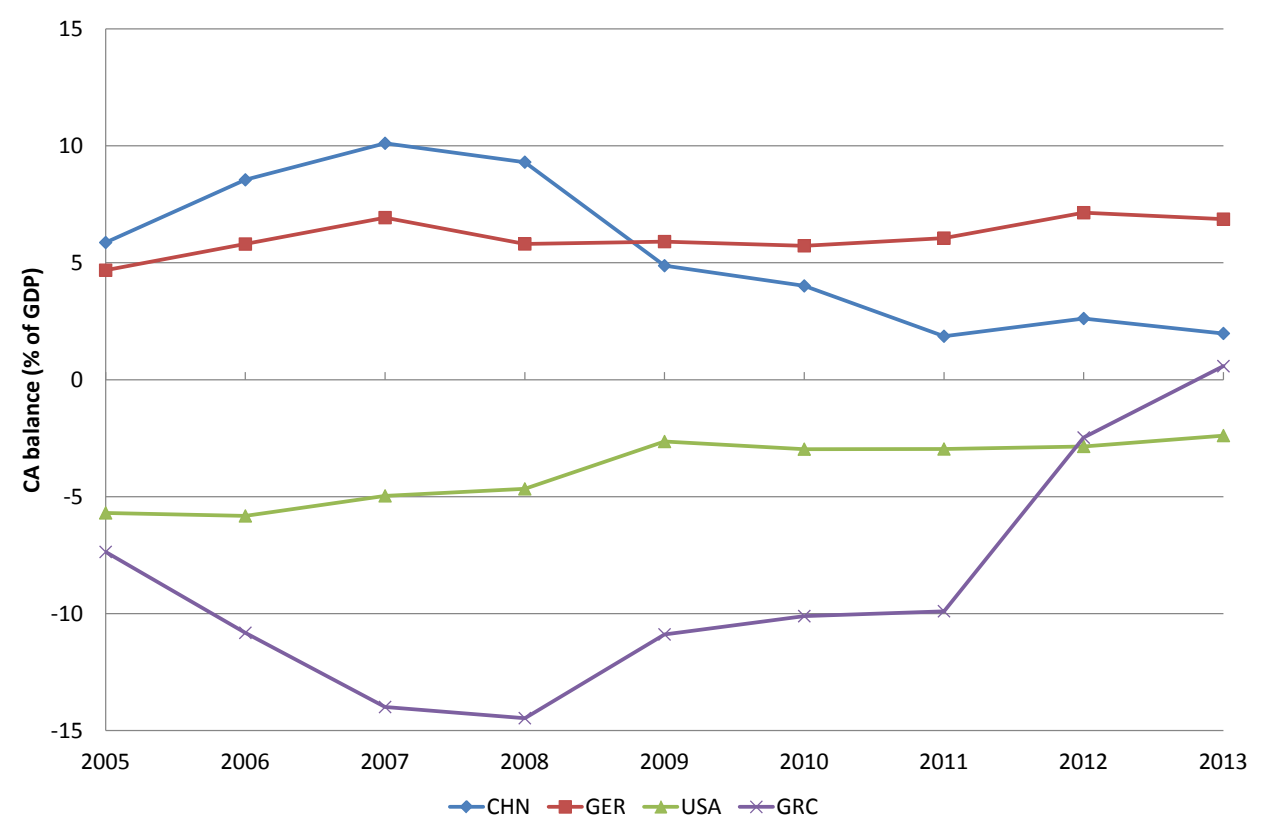

Figure 1: Current Account Imbalances. Source: World Development Indicators.

ing of its foreign trade? Similarly, how is it that trade imbalances within the Euro Area are associated with the economic hegemony of surplus countries (by most macroeconomic indicators) and the stagnation or even the collapse of deficit countries?

In this paper, we challenge the conclusions from the traditional approach and show that the so called "new trade theory" can provide radically different and so far overlooked answers to old questions. To this purpose, we explore the welfare effects of trade imbalances in the Dixit-Stiglitz-Krugman model of monopolistic competition. Differently from recent attempts at measuring well-known effects of rebalancing (such as the double burden of a trade surplus) using trade models suitable for quantitative analysis, our aim is to highlight some unconventional possibilities. To bring these out with the greatest clarity, the model is stylized. Yet, it builds on standard assumptions and it is useful for illustrating some possibilities that seem to have been largely neglected in earlier discussions. In addition, following the literature on international transfers, we study the effects of an exogenous imbalance without taking a stand on its causes.

In Section 2 we therefore formulate a two-sector, multi-country, general-equilibrium version of the model in Krugman (1980) that allows for an explicit analysis of trade imbalances. The model is standard in most respects: one sector produces a homogeneous good under perfect competition and constant returns to scale, and the other produces differentiated goods under monopolistic competition and costly trade. The main novelties are that the homogeneous good is nontraded and that trade imbalances arise whenever 
the exchange rate (i.e., the relative wage) is inconsistent with balanced trade. These are realistic features: the differentiated sector stands for manufacturing production, which is far more traded than services, and trade is not balanced in general. In contrast, many existing models of monopolistic competition (e.g., Helpman and Krugman, 1985, Melitz and Redding, 2014) assume that the homogeneous good is freely traded and that trade is balanced.

As in the traditional theory, in our model a trade surplus involves an income transfer to the deficit country and possibly a terms-of-trade deterioration. Unlike the standard theory, however, trade imbalances do not impose any double burden on surplus countries. This is because the model features a production-delocation effect, in that a trade surplus requires a reallocation of labor towards tradeables. In turn, as first shown in Venables (1987), in the presence of trade costs the resulting increase in the number of local manufacturing firms leads to a reduction in the local price index. A striking implication is that a trade surplus always leads to a reduction in the real price of traded goods which is ceteris paribus beneficial. Thus, a surplus involves a tradeoff, as it requires an income transfer on the one hand, and leads to a beneficial expansion in the traded sector on the other. The net welfare effect is, in general, ambiguous, and we show that it can be positive when the elasticity of substitution between traded goods is low and trade costs are high.

We also show, however, that in our baseline setup the net welfare effect is negative for reasonable parameter values. In Section 3 we therefore consider a richer setup in which we allow for manufacturing intermediates in the production of final goods. We find that intermediate goods, which account for more than two thirds of international trade, can dramatically change our quantitative and qualitative conclusions. In particular, we find that a trade surplus may lead to an appreciation of the exchange rate, to a terms-of-trade improvement and to a welfare increase under standard parameter configurations. We also simulate the model's behavior under two different scenarios replicating the imbalances of China and Germany, the two largest surplus countries in the world. We find that in both cases the beneficial price-index effect reduces significantly the direct cost of the transfer.

In Section 4, we perform a different but related thought experiment: rather than studying the price effect of an exogenous increase in the transfer, as in the previous Sections and in most of the literature, we study instead what happens if a government decides to fix the international relative wage, i.e., the exchange rate. For example, the Chinese government might have been intervening in the international capital markets so as to avoid any deterioration of the country's competitiveness. Alternatively, this scenario may also describe the short-run equilibrium of economies with a fixed exchange rate and nominal rigidities. Since in our model the general-equilibrium relationship between the 
exchange rate and the transfer is dictated by a trade-imbalance condition, one might suspect that fixing the exchange rate or the transfer is immaterial for the results. We find that, surprisingly, this is not the case in the presence of intermediate goods. The reason is that intermediate goods give rise to agglomeration economies through the cost and demand linkages between producers of intermediate and final goods, as in Krugman and Venables (1995). With fixed relative wages, agglomeration economies imply that depending on the parameter configurations the manufacturing sector may tend to concentrate in one country.

These results have far-reaching implications. They may help explain why a country like China, who resists the real appreciation of its currency through the accumulation of foreign reserves and capital controls, can become a 'world factory'. ${ }^{1}$ They also suggest that a fixed exchange rate and nominal rigidities may generate short-run instability with recurrent fluctuations of trade imbalances. Finally, these results also revisit some insights from the 'new economic geography' literature (e.g., Fujita, Krugman and Venables, 1999). In particular, we find that a crucial condition for agglomeration is the lack of adjustment of relative wages. ${ }^{2}$ So long as relative wages are endogenous, the symmetric equilibrium is always stable under balanced trade and agglomeration is impossible. Under a fixed exchange rate, instead, the model properties are the same as in Krugman and Venables (1995): the symmetric balanced-trade equilibrium may become unstable, in which case manufacturing firms start to agglomerate in the surplus country.

Besides the literature on the effects of rebalancing already mentioned (especially Dekle, Eaton and Kortum, 2007 and 2008, and Obstfeld and Rogoff, 2007), our paper is related to the classical debate on how international transfers affect the terms of trade and welfare for the donor and recipient countries. The large research effort that followed the controversy between Ohlin and Keynes has shown that, in theory, the terms-of-trade and welfare effects of a transfer can go either way (e.g., Bhagwati, Brecher and Hatta, 1983). Although a transfer could conceivably improve the donor's terms of trade so much as to increase its welfare, the conditions for this outcome are considered more stringent than those for immiserizing growth, and this possibility is therefore deemed a theoretical curiosity. In practice, the widespread presumption is that nontraded goods and costly trade generate a home bias in consumption, which implies that a transfer causes (i) a deterioration of the donors' terms of trade and hence (ii) a double burden. Our results challenge this

\footnotetext{
${ }^{1}$ In Song, Storesletten and Zilibotti (2011) a constant wage also plays a key role in explaining the Chinese growth miracle. However, in their model it is the result of labor reallocations, and not of government intervention.

${ }^{2}$ Helpman (1998) shows that nontraded goods can weaken agglomeration forces in a very different two-region model with labor mobility.
} 
conventional view. It is precisely in the presence of trade costs that the entry margin can turn the adverse terms-of-trade effect of the transfer into a favorable change of the price level in the donor country. Moreover, with traded intermediate inputs, production costs can fall so much in the donor country that a rise in wages (hence an improvement in the terms of trade) is needed to restore the equilibrium.

The closest paper to ours is Corsetti, Martin and Pesenti (2013), who develop a twocountry model of monopolistic competition to study how the entry margin affects the price effects of a transfer. Similarly to us, they find that the implications for prices can be very different when the adjustment occurs at the extensive margin. Differently from us, however, they do not find that entry can lower the real cost of the transfer for the sending country. The main reason for this difference is that they treat varieties and entry symmetrically in the traded and nontraded sector. On the contrary, to make our unconventional results transparent, we shut down the variety effect entirely in the nontraded sector, which is assumed to produce a homogeneous good. Besides delivering interesting new effects, our assumption is consistent with the evidence that scale economies are more prevalent in manufacturing sectors (for example, Buera and Kaboski, 2012, show that average firm scale is much larger in manufacturing than in services) and that trade costs are lower in more $\mathrm{R} \& \mathrm{D}$-intensive sectors in which intra-industry trade is more prevalent (e.g., Davis, 1998). In addition, Corsetti, Martin and Pesenti (2013) do not consider intermediate goods, which instead play an important role in our analysis.

This paper also contributes to the growing literature trying to bridge trade theory and international finance. Obstfeld and Rogoff (2000) were among the first to recognize that introducing explicitly trade costs helps explaining various puzzles in international macroeconomics. Ghironi and Melitz (2005) show that adding endogenous varieties contributes at explaining international business cycles. Although all these papers greatly improved our understanding of real and financial linkages, virtually all the models in this literature suffer from an important shortcoming: they cannot explain why competitive devaluations can be beneficial. The seemingly insurmountable obstacle so far has been that a devaluation corresponds to a deterioration of a country's terms of trade, which is usually welfare reducing. Yet, in our model the production-relocation effect implies that a devaluation expands the manufacturing sector, increases the number of local firms and has a beneficial effect on the price index. ${ }^{3}$ Hence it is plausible to expect, although here we do not try to formalize this intuition, that adding nominal rigidities to our model could yield competitive devaluations that are welfare improving, consistently with the conventional wisdom

\footnotetext{
${ }^{3}$ In a similar vein, Ossa (2011) shows that the production-delocation effect can help rationalize subsidies to export. See also Bagwell and Staiger (2015) and Campolmi, Fadinger and Forlati (2013).
} 
in policy circles. ${ }^{4}$

\section{The Price-Index Effect of Trade Imbalances}

\subsection{Baseline Setup}

Overview. Consider a world consisting of $N+1$ countries: Home, indexed by $i=h$, and $N$ Foreign, each indexed by $i=f$. While Home is allowed to differ from Foreign, for simplicity all the $N$ Foreign are identical to each other. There is one homogenous production factor, labor, with endowments $L_{h}$ and $L_{f}$. All countries produce a homogeneous nontraded good, $S$, and a differentiated traded good $M$ (henceforth, manufacturing goods). The nontraded good is produced under perfect competition, using one efficiency unit of labor to produce one unit of output. Following Corsetti, Martin and Pesenti (2013), we choose the wage per efficiency unit of labor as the numeraire in each country and denote by $\epsilon$ the exchange rate, defined as the price of Foreign's numeraire in terms of Home's. According to this convention, a rise of $\epsilon$ represents an exchange rate depreciation in Home. Due to symmetry, the exchange rate between any pair of Foreign is one. The traded sector is monopolistically competitive à la Dixit-Stiglitz: a large mass of symmetric firms produce differentiated goods using a fixed cost $f$ and a variable cost $1 / \theta$ in efficiency units of labor. International trade involves trade costs of the iceberg type: $\tau>1$ units must be shipped in order for one unit to arrive at the destination.

Preferences. Preferences are represented by the following quasi-linear utility function:

$$
U_{i}=C_{i}(S)+\ln C_{i}(M), \quad C_{i}(M)=\left(\int_{0}^{n} c_{i}(z)^{\frac{\sigma-1}{\sigma}} d z\right)^{\frac{\sigma}{\sigma-1}}
$$

$C_{i}(S)$ is consumption of a nontraded good; $C_{i}(M)$ is consumption of a CES aggregate of differentiated traded goods, indexed by $z \in n$, where $n$ is the total mass of manufacturing firms in all countries; $\sigma>1$ is the elasticity of substitution between any two traded goods. ${ }^{5}$

\footnotetext{
${ }^{4}$ The interaction between monetary policy and comparative advantage is studied in an interesting recent paper by Bergin and Corsetti (2015), who show in a model with monopolistic competition and sunk entry costs that stabilizing policies can foster competitiveness. See also Crino' and Epifani (2014) for an analysis of the distributional implications of trade imbalances in compararative advantage models.

${ }^{5}$ The above preferences imply that total expenditure on manufacturing goods is exogenous. The latter will be endogenized in the next Section, in which we assume that manufacturing goods are used both as final goods and as intermediates in the production of other manufacturing goods. In a robustness check we also study how the results are affected when preferences are Cobb Douglas rather than quasi linear.
} 
The ideal price index associated with $C_{i}(M)$ is:

$$
P_{i}=\left(\int_{0}^{n} \tilde{p}_{i}(z)^{1-\sigma} d z\right)^{\frac{1}{1-\sigma}}
$$

where $\tilde{p}_{i}(z)$ is the local-currency final price of variety $z$, gross of any trade cost.

Trade imbalances are modeled as a transfer $T_{i}$ from the surplus country (Home, i.e., $T_{h}>0$ ) to the $N$ deficit countries (Foreign, i.e., $T_{f}<0$ ) equal to the value of the trade surplus. Consequently, expenditure per capita equals $Y_{i}-T_{i} / L_{i}$, where $Y_{i}$ is the labor efficiency of one worker.

Maximization of (1) implies that $C_{i}(M) P_{i}=1$. Consumption of the nontraded good therefore equals: ${ }^{6}$

$$
C_{i}(S)=Y_{i}-1-T_{i} / L_{i}
$$

Substituting $C_{i}(S)$ and $C_{i}(M)=1 / P_{i}$ into (1) yields the indirect utility function: ${ }^{7}$

$$
V_{i}=Y_{i}-1-T_{i} / L_{i}-\ln P_{i}
$$

Evidently, welfare is decreasing in the transfer and in the price index of manufacturing goods, as both lead to a reduction in real expenditure. Observe that in the standard trade theory a trade surplus involves a transfer $T_{i}$ and a higher price index $P_{i}$ (due to the induced terms-of-trade deterioration) and is therefore unambiguously welfare reducing. As shown below, matters are more interesting in monopolistic competition.

Price Indexes. Goods-market equilibrium in Home requires the equality between supply and demand for each traded good:

$$
q_{h}=d_{h}+\tau N x_{h},
$$

where $q_{h}$ is the output; $d_{h}$ and $x_{h}$ are, respectively, the domestic and export demand for a good produced in Home. ${ }^{8}$ Similarly, for each Foreign-produced good:

$$
q_{f}=d_{f}+\tau x_{f h}+(N-1) \tau x_{f f},
$$

\footnotetext{
${ }^{6}$ Note that an interior equilibrium in which the nontraded good is produced in all countries requires $C_{i}(S)>0 \Leftrightarrow Y_{i}-1>T_{i} / L_{i}$, a condition always satisfied for $Y_{i}$ sufficiently high.

${ }^{7}$ For later use, note that total nominal income equals $Y_{i} L_{i}$ and that the share allocated to manufacturing is $1 / Y_{i}$.

${ }^{8}$ Note that we have dropped the variety index $z$ as goods are symmetric, and have multiplied export demand by $\tau$ to account for the iceberg nature of trade costs.
} 
where $d_{f}$ is local demand, $x_{f h}$ is demand from Home and $x_{f f}$ is demand from the other $(N-1)$ Foreign. Utility maximization implies:

$$
d_{i}=\frac{P_{i}^{\sigma-1} E_{i}}{p_{i}^{\sigma}}, \quad x_{h}=\frac{P_{f}^{\sigma-1} E_{f}}{\left(\tau p_{h} / \epsilon\right)^{\sigma}}, \quad x_{f h}=\frac{P_{h}^{\sigma-1} E_{h}}{\left(\tau p_{f} \epsilon\right)^{\sigma}}, \quad x_{f f}=\frac{P_{f}^{\sigma-1} E_{f}}{\left(\tau p_{f}\right)^{\sigma}},
$$

where $p_{i}$ is the local-currency price of a locally produced good, and $E_{i}=L_{i}$ is the total expenditure on manufacturing goods in country $i$. As usual, demand for a given good is increasing in the price index $P_{i}$ and decreasing in its own price, with an elasticity equal to $\sigma$. Hence, a depreciation (a rise of $\epsilon$ ) raises Home firms' exports at the expense of Foreign's.

Profit maximization and symmetry in $\theta$ imply $p_{h}=p_{f}=p=\frac{\sigma}{\sigma-1} \frac{1}{\theta}$. Hence the Home terms of trade, defined as the common-currency price of imports in terms of exports, are simply equal to $\epsilon$ in this baseline model. Free entry and symmetry in $f$ imply instead a break-even level of output equal to $q_{h}=q_{f}=q=f(\sigma-1) \theta$. Without loss of generality, from now on we normalize $p=1$ and $q=1$. Thus, using (6) in (4) and (5) yields:

$$
\begin{aligned}
1 & =P_{h}^{\sigma-1} E_{h}+\phi \epsilon^{\sigma} P_{f}^{\sigma-1} N E_{f}, \\
1 & =P_{f}^{\sigma-1} E_{f}[1+\phi(N-1)]+\phi \epsilon^{-\sigma} P_{h}^{\sigma-1} E_{h},
\end{aligned}
$$

where $\phi \equiv \tau^{1-\sigma} \in(0,1)$ is a measure of trade freeness. These free-entry conditions imply a negative relationship between $P_{h}$ and $P_{f}$ : to keep sales unchanged, a fall in Foreign demand must be compensated by a rise in Home demand. Moreover, since firms do not have to pay the transport cost to sell in their domestic market, the Home market is relatively more important to Home firms than it is to Foreign firms.

Solving (7) for $P_{h}$ and $P_{f}$ yields an expression for the two price indexes:

$$
\begin{aligned}
P_{h}^{\sigma-1} & =\frac{1-\phi+N \phi-N \phi \epsilon^{\sigma}}{E_{h}(1-\phi)(1+N \phi)}, \\
P_{f}^{\sigma-1} & =\frac{1-\phi \epsilon^{-\sigma}}{E_{f}(1-\phi)(1+N \phi)} .
\end{aligned}
$$

Strikingly, $P_{h}$ is monotonically decreasing in $\epsilon$ and $P_{f}$ is monotonically increasing in $\epsilon$ in the feasible range. Thus, a depreciation of Home's exchange rate (a rise of $\epsilon$ ) leads to a reduction in the Home price index and to an increase in the Foreign price index. The intuition for this result is as follows. An increase in $\epsilon$ makes Home producers relatively more competitive. To restore free entry, demand must fall for Home firms and rise for Foreign firms. Since Home firms are relatively more sensitive to local demand, the adjustment can 
only happen through a reduction in $P_{h}$ and an increase in $P_{f} .{ }^{9}$

The fall in the local price index after a depreciation may sound paradoxical at first. After all, an increase in $\epsilon$ makes imported varieties more expensive and this tends to increase the price index. So, how can the adjustment take place? The answer, as we show formally next, is through a change in the mass of Home and Foreign firms.

Mass of Firms. We now determine the equilibrium mass of Home and Foreign firms, $n_{h}$ and $n_{f}$ respectively. Using (2) yields:

$$
\begin{aligned}
P_{h}^{1-\sigma} & =n_{h}+\phi \epsilon^{1-\sigma} N n_{f}, \\
P_{f}^{1-\sigma} & =\phi \epsilon^{\sigma-1} n_{h}+n_{f}(1-\phi+N \phi) .
\end{aligned}
$$

Solving (9) for $n_{h}$ and $n_{f}$, and using (8), yields:

$$
\begin{aligned}
& n_{h}=\frac{E_{h}(1-\phi+N \phi)}{1-\phi+N \phi-N \phi \epsilon^{\sigma}}-\frac{E_{f} N \phi \epsilon^{1-\sigma}}{1-\phi \epsilon^{-\sigma}}, \\
& n_{f}=\frac{E_{f}}{1-\phi \epsilon^{-\sigma}}-\frac{E_{h} \phi \epsilon^{\sigma-1}}{1-\phi+N \phi-N \phi \epsilon^{\sigma}} .
\end{aligned}
$$

Note that $n_{h}$ is increasing in $\epsilon$ and $n_{f}$ decreasing: a depreciation, by increasing the profitability of Home firms at the expense of Foreign firms, induces firm delocation from Foreign to Home. In turn, given that Home consumers save the trade cost on the varieties whose production has moved from the Foreign country, the price index falls in Home and rises in Foreign. This result, that a devaluation lowers the price index due to the change in the number of firms, is similar to the production-delocation effect first noticed by Venables (1987) in the context of an iceberg import tariff.

Trade Imbalances. The local-currency value of Home's exports (gross of trade costs) equals $X_{h}=p_{h} \tau x_{h} N n_{h}$. Thus, using (6),

$$
X_{h}=N E_{f} \epsilon^{\sigma} \phi P_{f}^{\sigma-1} n_{h}
$$

Similarly, the gross exports of the $N$ Foreign countries to Home are:

$$
X_{f}=N E_{h} \epsilon^{-\sigma} \phi P_{h}^{\sigma-1} n_{f}
$$

\footnotetext{
${ }^{9}$ Notice also that Home firms are more sensitive to changes in the local price index the larger the size of the local market $E_{h}$. Hence, for a given depreciation, the fall in the local price index will be smaller in a large country.
} 
Hence, the local-currency value of Home's trade surplus, $T_{h}=X_{h}-\epsilon X_{f}$, equals:

$$
T_{h}=\phi N\left(E_{f} \epsilon^{\sigma} P_{f}^{\sigma-1} n_{h}-E_{h} \epsilon^{1-\sigma} P_{h}^{\sigma-1} n_{f}\right)
$$

Using (8) and (10) in (11) yields our key trade-imbalance condition:

$$
T_{h}=\phi N\left(\frac{\epsilon^{\sigma} E_{h}}{1-\phi+N \phi-N \phi \epsilon^{\sigma}}-\frac{E_{f} \epsilon^{1-\sigma}}{1-\phi \epsilon^{-\sigma}}\right) .
$$

Importantly, equation (12) dictates the general equilibrium relationship between $T_{h}$ and $\epsilon$. Simple inspection reveals that $T_{h}$ is increasing in $\epsilon$ : hence, a trade surplus leads to a depreciation of the exchange rate in this baseline model.

Notice that, imposing $T_{h}=0$, equation (12) pins down the exchange rate $\epsilon$, and thus the terms of trade, consistent with balanced trade. It is easy to show that, if countries are symmetric, then $T_{h}=0$ implies $\epsilon=1$. In the presence of asymmetries, instead, the relative wage and the terms of trade will tend to be higher in the country with a larger domestic market (high $L_{i}$ ). The latter result is a consequence of the familiar "home market effect".

We summarize the main comparative statics to a change in $T_{h}$ in the following Proposition:

Proposition 1 A transfer $T_{h}$ from Home to Foreign leads to: a) a depreciation of the exchange rate $\epsilon$ (a reduction in Home's relative wage and a terms-of-trade deterioration), b) an increase in the mass of manufacturing firms $n_{h}$, and c) a reduction in the price index $P_{h}$, i.e.,

$$
\frac{d \epsilon}{d T_{h}}>0 ; \quad \frac{d n_{h}}{d T_{h}}>0 ; \quad \frac{d P_{h}}{d T_{h}}<0
$$

When $N=L_{h}=L_{h}=1$ :

$$
\frac{d \epsilon}{d T_{h}}=\frac{(1-\phi)^{2}}{[2 \sigma-(1-\phi)] \phi} ; \quad \frac{d \ln n_{h}}{d T_{h}}=\frac{\phi[2 \sigma-(1-\phi)]}{1-\phi^{2}} \frac{d \epsilon}{d T_{h}} ; \quad \frac{d \ln P_{h}}{d T_{h}}=-\frac{\phi}{1-\phi} \frac{\sigma}{\sigma-1} \frac{d \epsilon}{d T_{h}}
$$

\subsection{The Transfer Problem Revisited}

We are now in the position to discuss the welfare effects of a transfer $T_{h}$ from Home to Foreign. Home transfers tradeable varieties for a value $T_{h}$ to Foreign. Given quasi-linear preferences, at constant prices this additional income would be absorbed entirely by an increase in consumption of the Foreign nontraded good, which requires a reallocation of Foreign labor away from the traded sectors. Similarly, the fall in Home income would be absorbed by lowering consumption of the nontraded good, which requires a reallocation of Home labor to the traded sector. Given that firm size is fixed, $n_{h}$ rises and $n_{f}$ falls. 
In the absence of trade costs, this substitution of firms would not affect prices, and this would be the end of the story. However, in the presence of trade costs, the relocation of production reduces the price index in the Home country, where there are now more active firms, and raises it in the Foreign country, where fewer firms are left. In turn, the fall in $P_{h}$ and the rise in $P_{f}$ lower the demand for Home goods and raise the demand for Foreign goods. To restore the equilibrium, the Home wage must fall relative to Foreign, which corresponds to a depreciation of the exchange rate (higher $\epsilon$ ). The effect of a small transfer on the total number of varieties is in general ambiguous as it depends on the nature of country asymmetries. If the countries are symmetric, however, the fall in $P_{h}$ is exactly compensated by the rise in $P_{f}$ and the total number of firms does not change.

Notice that, similarly to standard models, the transfer leads to a terms-of-trade deterioration for the sending country. However, contrary to those models, the variety effect implies that this terms-of-trade deterioration is, in itself, welfare improving for the sending countries. Thus, what has been so far considered a "double burden" can actually alleviate the welfare cost of a transfer.

More formally, recall that Home welfare is given by:

$$
V_{h}=Y_{h}-1-T_{h} / L_{h}-\ln P_{h}
$$

The change in Home welfare after a transfer $T_{h}$ is

$$
\Delta V_{h}=-\frac{T_{h}}{L_{h}}+\ln \frac{P_{h, 0}}{P_{h, T}}
$$

where $P_{h, 0}$ and $P_{h, T}$ are the Home price indexes with $T_{h}=0$ and $T_{h}>0$, respectively. The first term is the direct cost of the transfer, the second is the effect due to the change in the price index. In turn, the latter effect can be expressed as

$$
\ln \frac{P_{h, 0}}{P_{h, T}}=\frac{1}{\sigma-1} \ln \frac{1-\phi+N \phi-N \phi \epsilon_{0}^{\sigma}}{1-\phi+N \phi-N \phi \epsilon_{T}^{\sigma}} .
$$

Let $\Delta \widetilde{V}_{h}=-T_{h} / L_{h}$ be the hypothetical welfare cost of the transfer at constant prices. Hence, the real cost of the transfer relative to a model with no price index effect, denoted by $T_{R}$, is

$$
T_{R} \equiv \frac{\Delta V_{h}}{\Delta \widetilde{V}_{h}}=1-\frac{L_{h}}{T_{h}(\sigma-1)} \ln \left(\frac{1-\phi+N \phi-N \phi \epsilon_{0}^{\sigma}}{1-\phi+N \phi-N \phi \epsilon_{T}^{\sigma}}\right) .
$$

We will use $T_{R}$ as a metric to assess by how much the price index effect can lower the real cost of a given transfer. In particular, notice that $T_{R}=1$ if $\epsilon_{0}=\epsilon_{T}$, that is, when relative wages do not move. As long as $\epsilon_{T}>\epsilon_{0}$, the depreciation in Home is associated with a 
lower price index, which reduces the real cost of the transfer by the factor $T_{R}<1$.

Can the price index effect be so large as to make the transfer welfare improving for the surplus country? In other words, can $T_{R}$ turn negative? The striking answer is yes, as stated formally below:

Proposition 2 The effect on Home welfare of a transfer $T_{h}$ to Foreign is ambiguous:

$$
\frac{d V_{h}}{d T_{h}}=-1 / L_{h}-\frac{d \ln P_{h}}{d \epsilon} \frac{d \epsilon}{d T_{h}} .
$$

When $N=L_{h}=L_{h}=1$, in a neighborhood of $T_{h}=0$ :

$$
\frac{d V_{h}}{d T_{h}}>0 \quad \text { iff } \quad \frac{\sigma}{\sigma-1} \frac{1-\phi}{2 \sigma+\phi-1}>1 .
$$

In the special case of $N=1$ (two countries) and no asymmetries between Home and Foreign, the determinants of the beneficial price-index effect can be easily characterized analytically: a transfer is more likely to be welfare increasing for low values of $\sigma$ and high trade costs, $\tau$. For standard parameter values the net welfare effect is negative. As we show in the next section through numerical simulations, however, the positive priceindex effect can be significant, making up for 25 percent of the direct cost of the transfer. Thus, unlike the traditional trade theory, in which a terms-of-trade deterioration adds up to the direct cost of the transfer, in the Dixit-Stiglitz-Krugman model of monopolistic competition the net cost of the transfer is always less than its direct cost.

So far, we have seen that a trade surplus leads to a fall in prices which increases the purchasing power in Home. Besides being derived from conventional assumptions, this result is also realistic. For instance, the fact that Chinese consumers benefited from the relocation of industrial production to their home country is hard to dispute. Yet, this is probably the less important part of the story. As we show in the next Section, in the presence of traded intermediates, agglomeration of industrial production is not just beneficial for consumers, it also improves the competitiveness of Chinese firms.

\section{Imbalances with Intermediate Goods}

Intermediate goods play a prominent role in international trade. As already noted by Ethier (1982) more than thirty years ago, "I cannot resist the temptation to point out that producers' goods are in fact much more prominent in trade than are consumers' goods". Recent estimates confirm his insight: by now, intermediate products account for about two-thirds of the volume of world trade.

In the rest of the paper we therefore consider a more general setup in which differen- 
tiated intermediate goods are used in the production of final goods. Following the related literature and the previous Section, we begin by treating the transfer as exogenous and the exchange rate as endogenous. In the next Section, we will consider instead a setup in which the Home country's government can peg the exchange rate and the transfer is therefore endogenous.

\subsection{The Model with Intermediates}

To model intermediate goods, we follow Krugman and Venables (1995). Specifically, we assume that the total cost function (in units of local currency) of a manufacturing firm located in country $i$ is

$$
T C_{i}=\left(f+\frac{q}{\theta}\right) P_{i}^{\mu} w_{i}^{1-\mu},
$$

where $w_{i}=1$ is the wage and $P_{i}$ is the price index of manufacturing goods. This formulation implies that manufacturing goods enter the production function for other manufacturing goods (as intermediates) and the utility function (as final goods) through the same CES aggregator. More importantly, the price and marginal cost of a manufacturing good are now decreasing in the local price index:

$$
p_{i}=\frac{\sigma}{\sigma-1} \frac{P_{i}^{\mu}}{\theta}=P_{i}^{\mu}
$$

where the latter equality follows from our normalization.

This formulation gives rise to agglomeration economies through the cost linkages between producers of intermediates and final goods. This is because agglomeration allows local producers of final goods to save on the trade costs of intermediate inputs, which reduces $P_{i}$ and therefore increases, ceteris paribus, the revenue and profits of manufacturing firms.

Eq. (13) also implies that in each country the total expenditure on intermediate goods is a constant share $\mu$ of the value of local manufacturing production. As a consequence, country $i$ 's total expenditure on manufacturing goods is now endogenous and is given by:

$$
E_{i}=L_{i}+\mu p_{i} n_{i}
$$

Eq. (15) gives rise to agglomeration economies through the demand linkages between producers of intermediates and final goods. This is because agglomeration leads to an increase in firms' sales of intermediate inputs and therefore increases, ceteris paribus, their revenue and profits. 
As in the previous Section, using (14) in (6) and (4) we can solve for the price indexes:

$$
\begin{aligned}
P_{h}^{\sigma-1} & =\frac{p_{h}^{\sigma}(1-\phi+N \phi)-N \phi \epsilon^{\sigma} p_{f}^{\sigma}}{E_{h}(1-\phi)(1+N \phi)}, \\
P_{f}^{\sigma-1} & =\frac{p_{f}^{\sigma}-\phi \epsilon^{-\sigma} p_{h}^{\sigma}}{E_{f}(1-\phi)(1+N \phi)} .
\end{aligned}
$$

To express the equilibrium mass of Home and Foreign firms, we solve for $n_{h}$ and $n_{f}$ from the price index (2):

$$
\begin{aligned}
& n_{h}=p_{h}^{\sigma-1}\left[\frac{E_{h}(1-\phi+N \phi)}{p_{h}^{\sigma}(1-\phi+N \phi)-N \phi \epsilon^{\sigma} p_{f}^{\sigma}}-\frac{E_{f} \phi \epsilon^{1-\sigma} N}{p_{f}^{\sigma}-\phi \epsilon^{-\sigma} p_{h}^{\sigma}}\right], \\
& n_{f}=p_{f}^{\sigma-1}\left[\frac{E_{f}}{p_{f}^{\sigma}-\phi \epsilon^{-\sigma} p_{h}^{\sigma}}-\frac{E_{h} \phi \epsilon^{\sigma-1}}{p_{h}^{\sigma}(1-\phi+N \phi)-N \phi \epsilon^{\sigma} p_{f}^{\sigma}}\right] .
\end{aligned}
$$

Finally, the local-currency value of Home's trade surplus equals $T_{h}=X_{h}-\epsilon X_{f}$, where $X_{h}=p_{h} \tau x_{h} N n_{h}$ and $X_{f}=p_{f} \tau x_{f} N n_{f}$. Hence, using (17) we obtain:

$$
T_{h}=\phi N\left[\frac{p_{f}^{\sigma} \epsilon^{\sigma} E_{h}}{p_{h}^{\sigma}(1-\phi+N \phi)-N \phi \epsilon^{\sigma} p_{f}^{\sigma}}-\frac{p_{h}^{\sigma} \epsilon^{1-\sigma} E_{f}}{p_{f}^{\sigma}-\phi \epsilon^{-\sigma} p_{h}^{\sigma}}\right] .
$$

Using (14) in (15), (16), (17), and (18) yields a system of 5 equations in $P_{h}, P_{f}, E_{h}, E_{f}$ and $\epsilon$.

\subsection{Transfer and Prices: Analytic Results}

The above system is highly non linear and does not admit in general analytic solutions. Hence, to gain insight on the model's mechanics, we begin by considering a simplified symmetric two-country version of the model in which we study the comparative-statics effects of a small transfer in neighborhood of the symmetric, zero transfer, equilibrium. The analysis is greatly simplified because the symmetric equilibrium (with $T_{i}=0$ ) is easy to characterize. Linearizing the system we can prove (see the Appendix) the following results:

Proposition 3 Assume that $\sigma(1-\mu)>1$ and $N=L_{h}=L_{f}=1$. Then, in a neighborhood of $T_{i}=0$, a small transfer from Home to Foreign lowers the price index in Home:

$$
\frac{d \ln P_{h}}{d T_{h}}<0
$$


The effect of the transfer on the exchange rate (Home's relative wage) is instead ambiguous:

$$
\frac{d \ln \epsilon}{d T_{h}}<0 \quad \text { iff } \quad \tau^{\sigma-1}<\frac{(1+\mu)(\sigma+\sigma \mu-1)}{(1-\mu)(\sigma-\sigma \mu-1)}
$$

Thus, as in the baseline model, a trade surplus leads to a reduction in the price index in the relevant range (i.e., for $\sigma(1-\mu)>1) .{ }^{10}$ However, unlike in the baseline model, the sign of $d \epsilon / d T_{h}$ is now in general ambiguous. In particular, $d \epsilon / d T_{h}$ turns negative when agglomeration forces are strong enough, namely, when $\mu$ is sufficiently large, or $\sigma$ and $\tau$ are sufficiently low. The intuition for this surprising result is simple: by inducing the expansion in the traded sector, a trade surplus strengthens agglomeration forces, and when these are strong enough, they are the key determinant of a country's competitiveness. It follows that the push to competitiveness given by agglomeration forces may require an offsetting appreciation, rather than a depreciation, of the exchange rate.

\subsection{Simulations}

We now turn to numerical examples. To start with, we show the effects of non-infinitesimal transfers in the symmetric case. Panel a) of Figure 2 plots $V_{h, T}-V_{h, 0}$, where $V_{h, 0}$ is Home welfare in $T_{h}=0$, as a function of $T_{h}$ for different values of $\mu$, the key parameter regulating the strength of agglomeration forces in our model. ${ }^{11}$ In all cases we set $\sigma=3$ and $\tau=2.7$. Note that, for $\mu=0$, we are back in the baseline setup and welfare is monotonically decreasing in the trade surplus relative to the balanced-trade equilibrium. For $\mu=0.3$ and $\mu=0.4$ the qualitative results are unchanged, but the curve is less steep, the more so the higher is $\mu$. Finally, for $\mu=0.5$ the results are reversed: welfare is now an inverted-U function of $T_{h}$. In other words, when agglomeration forces are strong enough, a small transfer is welfare improving and there is an interior level of $T_{h}$ that maximizes Home utility. This non-monotonicity of welfare with respect to the transfer is due to the endogenous response of the exchange rate to $T_{h}$ : as shown in panel b), when agglomeration forces are strong, an increase in the transfer leads to a large appreciation of the exchange rate for high $T_{h}$; in turn, a fall of $\epsilon$ leads, ceteris paribus, to an increase in the price index that adversely affects welfare.

Finally, Panel c) plots the terms of trade, i.e., the common-currency price of imported

\footnotetext{
${ }^{10}$ This is the so-called no-black-hole condition (see, e.g., Fujita et al. 1999, p. 58). It is equivalent to assuming that agglomeration forces are not too strong. Note also that, in the presence of intermediate goods, the monopolistic distortion is captured by the term $[\sigma(1-\mu)-1]^{-1}$, and that the latter becomes negative when the no-black-hole condition is violated, a case arguably difficult to intepret. This provides a further justification for the standard assumption that $\sigma(1-\mu)>1$.

${ }^{11}$ Note that, ignoring exogenous terms, $V_{h, 0}=-\ln P_{h, 0}=-\frac{1}{\sigma(1-\mu)-1} \ln \frac{1-\mu}{1+\phi}$ (see the Appendix).
} 
a) Welfare

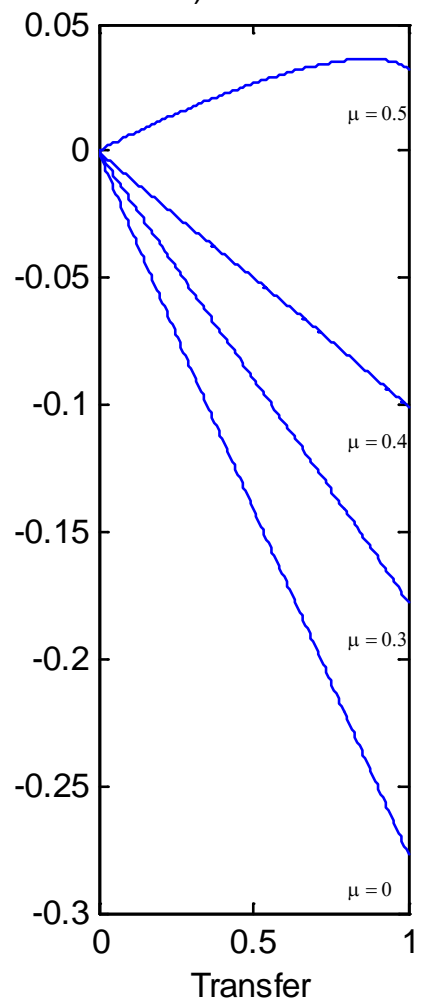

b) Exchange Rate

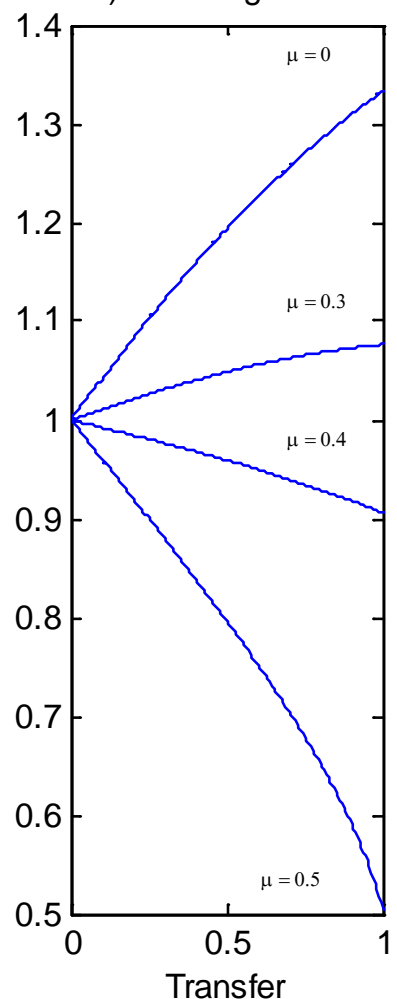

c) Terms of Trade

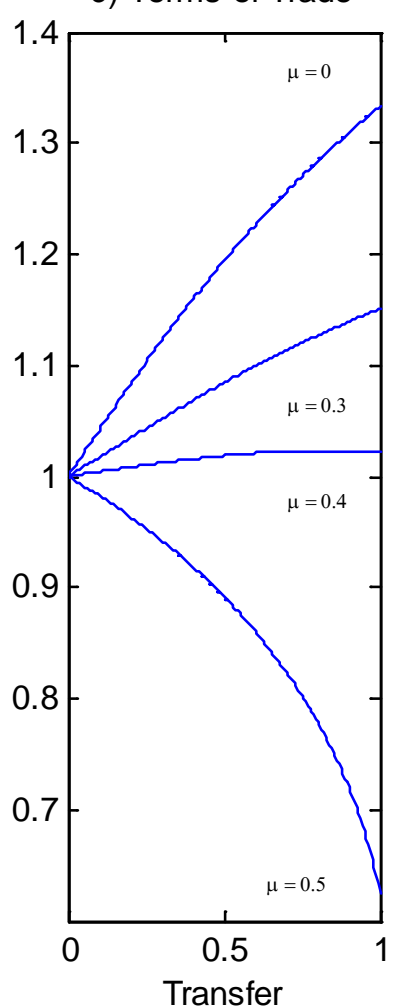

Figure 2: Imbalances, Welfare and Prices. Home welfare (panel a), exchange rate (panel b) and Home's terms of trade (panel c) as a function of $T_{h}$, starting from the symmetric equilibrium.

relative to exported goods, which are now equal to $\epsilon p_{f} / p_{h}=\epsilon\left(P_{f} / P_{h}\right)^{\mu}$. Note that, for $\mu=0.5$, a trade surplus leads to a terms-of-trade improvement. Thus, when agglomeration forces are strong enough, a trade surplus may involve a terms-of-trade appreciation and a welfare increase: the implications of the standard trade theory are now completely reversed!

After having understood the qualitative properties and the range of admissible outcomes, we now simulate the model under two scenarios that account for more realistic asymmetries across countries. In the first scenario, we consider a surplus country (Home) with the economic size of China trading with two countries (Foreign) that capture broadly the United States and Europe. We normalize the labor force of China to one, $L_{h}=1$, and set $L_{f}=0.5$, so as to match the observation that the non-rural labor force in China is roughly equal to the combined labor force of the United States and Europe. We then set $Y_{h}=3.3$, roughly consistent with the observation that the manufacturing share of GDP in China is 0.31 (World Bank). We also set $Y_{f}=2 * Y_{h}$ so that China, Europe and the United States have approximately the same aggregate economic size. With these parameters, we 


\begin{tabular}{|c|c|c|c|c|c|c|c|c|}
\hline & \multicolumn{4}{|c|}{$\bar{\mu} \mu=0$} & \multicolumn{4}{|c|}{$\mu=0.51$} \\
\hline & \multicolumn{2}{|c|}{$\sigma=5$} & \multicolumn{2}{|c|}{$\sigma=3$} & \multicolumn{2}{|c|}{$\sigma=5$} & \multicolumn{2}{|c|}{$\sigma=3$} \\
\hline & $\tau=1.7$ & $\tau=2.7$ & $\tau=1.7$ & $\tau=2.7$ & $\tau=1.7$ & $\tau=2.7$ & $\tau=1.7$ & $\tau=2.7$ \\
\hline & $(1)$ & $(2)$ & $(3)$ & $(4)$ & $(5)$ & $(6)$ & $(7)$ & $(8)$ \\
\hline$T_{R}$ & 0.876 & 0.816 & 0.836 & 0.748 & 0.585 & 0.446 & 0.434 & -0.045 \\
\hline$\Delta \% \epsilon$ & 3.28 & 23.19 & 1.01 & 4.96 & -2.53 & 8.92 & -5.84 & -11.24 \\
\hline$\Delta \% n_{h}$ & 6.66 & 6.66 & 6.66 & 6.66 & 8.18 & 8.69 & 8.73 & 10.51 \\
\hline$\Delta \% n_{f}$ & -6.87 & -5.83 & -7.09 & -7.08 & -10.69 & -10.43 & -13.02 & -21.32 \\
\hline
\end{tabular}

Table 1: Numerical Simulations: China

study the effect of a transfer from Home equal to $2 \%$ of its GDP.

In the second scenario, we consider a surplus country (Home) with the economic size of Germany trading with twenty-seven countries (Foreign) that capture the other EU member states. We normalize the labor force of Germany to one, $L_{h}=1$, and set $L_{f}=0.2$ so as to match the fact that Germany accounts for about $16 \%$ of the combined EU population. We then set $Y_{h}=6$ to obtain a manufacturing share of 0.16 , consistent with the EU average, and $Y_{f}=4.5$. The latter figure matches the observation that GDP per capita in the average EU country is about $75 \%$ of the German level. In the case of Germany, we study the effect of a transfer from Home equal to $4 \%$ of its GDP.

Regarding the remaining parameters, we experiment with various combinations. To assess the role of intermediate inputs, we consider the version of the model with no intermediates, $\mu=0$, and the more realistic case in which their cost share is $\mu=0.51$, which is consistent with the US input-output table. ${ }^{12}$ As for the elasticity of substitution between product varieties, we consider two values: $\sigma=3$, which is close to the "macro" estimates often used in studies on current account adjustments, and $\sigma=5$, which is closer to the "micro" estimates often used in the trade literature. Finally, we use two values also for the iceberg trade cost: $\tau=2.7$, as in Corsetti, Martin and Pesenti (2013), consistent with Anderson and van Wincoop's (2007) tax-equivalent estimate of overall trade costs of $170 \%$ for industrialized countries; and a more moderate level $\tau=1.7$, as in Melitz and Redding (2015).

The main effects of the transfer in the first scenario are reported in Table 1. It shows the real cost of one unit of the transfer, $T_{R}$, and the percentage change in the exchange rate, $\Delta \% \epsilon$, and in the number of Home and Foreign manufacturing firms, $\Delta \% n_{h}$ and $\Delta \%_{f}$,

\footnotetext{
${ }^{12}$ This figure is the ratio of manufacturing intermediates to value added plus intermediates, from Yamano and Ahmad (2006). Manufacturing intermediates are not used in the nontraded sector, consistently with the observation that services use intermediate inputs much less intensively. We relax this assumption in the next section.
} 


\begin{tabular}{|c|c|c|c|c|c|c|c|c|}
\hline & \multicolumn{4}{|c|}{$\bar{~} \mu=0$} & \multicolumn{4}{|c|}{$\mu=0.51$} \\
\hline & \multicolumn{2}{|c|}{$\sigma=5$} & \multicolumn{2}{|c|}{$\sigma=3$} & \multicolumn{2}{|c|}{$\sigma=5$} & \multicolumn{2}{|c|}{$\sigma=3$} \\
\hline & $\tau=1.7$ & $\tau=2.7$ & $\tau=1.7$ & $\tau=2.7$ & $\tau=1.7$ & $\tau=2.7$ & $\tau=1.7$ & $\tau=2.7$ \\
\hline & (1) & (2) & (3) & (4) & (5) & (6) & (7) & (8) \\
\hline$T_{R}$ & 0.919 & 0.858 & 0.917 & 0.840 & 0.729 & 0.543 & 0.721 & 0.351 \\
\hline$\Delta \% \epsilon$ & 1.33 & 10.67 & 0.36 & 2.00 & -4.64 & -2.51 & -5.26 & -12.61 \\
\hline$\Delta \% n_{h}$ & 24.00 & 24.00 & 24.00 & 24.00 & 28.18 & 31.13 & 28.31 & 34.25 \\
\hline$\Delta \% n_{f}$ & -4.76 & -4.66 & -4.70 & -4.97 & -7.35 & -10.57 & -7.01 & -13.29 \\
\hline
\end{tabular}

Note: transfer equal to $4 \%$ of $Y_{h}, L_{h}=1, L_{f}=0.2, N=27, Y_{h}=6, Y_{f}=0.75 * Y_{h}$.

Table 2: Numerical Simulations: Germany

respectively. Recall that $T_{R}=1$ in the absence of price effects, and that an increase in $\epsilon$ (a depreciation of Home's exchange rate) also corresponds to a reduction in Home's relative wage. In all cases, the fall in the Home price index has significant favorable effects on Home welfare, although the magnitude varies notably across the parameter space. The price effect is weakest in column (1), corresponding to no intermediates, low trade costs and high elasticity. Yet, even in this case, the price effect lowers the cost of the transfer to $87 \%$ of its value. Either a lower value of $\sigma$ or higher trade costs can cut the cost to almost $80 \%$ (columns 2 and 3) and to $75 \%$ if both holds (column 4). The effects are much larger in the presence of intermediate inputs. The price effect is now likely to reduce by about half the cost of the transfer (columns 5, 6 and 7). In the most extreme case (column 8), corresponding nonetheless to parameter values used in the literature, the transfer is actually welfare improving for the sending country!

Looking at the impact on the exchange rate, Table 1 shows significant heterogeneity across specifications. Without intermediate goods, the transfer leads to a fall in the Home relative wage by between $1 \%$ and $23 \%$ (columns 1-4). However, if we exclude the case $\sigma=5, \tau=2.7$, which is probably not the most realistic combination, the wage adjustment is of a few percentage points. ${ }^{13}$ With intermediate goods, instead, the transfer typically leads to a rise in the Home relative wage (again, excluding the case $\sigma=5, \tau=2.7$ ). The appreciation ranges from $2.5 \%$ to $11 \%$. Finally, in all cases, the transfer triggers a large relocation of firms from Foreign to Home of an order of magnitude around $6 \%-13 \%$ of existing firms. The relocation effect is especially strong in the presence of intermediate goods.

The effect of the transfer in the second scenario is reported in Table 2. Compared to the previous case, all price effects are now smaller. This is because Germany is smaller than China, and hence a given surplus (as a share of GDP) involves smaller general

\footnotetext{
${ }^{13}$ The combination of high $\sigma$ and high $\tau$ tends to yield too little trade.
} 
equilibrium effects. Yet, given the lower manufacturing share in this scenario, the change in the number of Home firms is now larger and as a result, the price index effect can still lower significantly the cost of the transfer, to $92 \% / 35 \%$ of its value.

\subsection{Robustness}

So far, we have purposedly relied on a number of simplifying assumptions in order to put our results in sharper relief and make our analysis more transparent. We are now in the position to discuss how relaxing some of these assumptions affects the main results. In particular, we have assumed that preferences are non homothetic and quasi linear, in this following a large theoretical literature on trade policy. Quasi-linear preferences are analytically convenient but somewhat restrictive, as they imply no income effects in the demand for manufacturing goods, and a constant marginal utility from consumption of the nontraded good.

We now assume, instead, that preferences are homothetic and Cobb Douglas. Although the latter are not necessarily more realistic than quasi-linear preferences, ${ }^{14}$ they tend to weaken our results for two main reasons. First, because Cobb-Douglas preferences imply a decreasing (rather than a constant) marginal utility from consumption of the nontraded good, and therefore an increasing opportunity cost of expanding the manufacturing sector after a trade surplus. Second, because with Cobb-Douglas preferences a trade surplus implies, ceteris paribus, a fall of (rather than a constant) expenditure on manufacturing goods, and therefore a smaller size of the domestic market and weaker agglomeration forces. In this Section we therefore want to quantify by how much our results are weakened under reasonable parameter configurations when preferences are Cobb Douglas rather than quasi linear.

Moreover, so far we have assumed that manufacturing intermediate goods are used only in the production of manufacturing goods. Although this is a reasonable approximation, allowing for traded manufacturing inputs also in the production function for the nontraded good should weaken our results, as this reduces the asymmetry between the traded and nontraded sector which is key to our main results. The question that the we would like to address now is by how much. To this end, in this Section we assume that the local-currency price and unit cost of the nontraded good in country $i$ is

$$
P_{i}(S)=P_{i}^{\mu_{s}} w_{i}^{1-\mu_{s}}=P_{i}^{\mu_{s}}
$$

\footnotetext{
${ }^{14}$ Cobb-Douglas preferences imply constant expenditure shares across countries, a counterfactual implication.
} 
where $w_{i}=1$ is the wage, $P_{i}$ the price index of manufacturing goods, and $\mu_{s}$ is the cost and revenue share of manufacturing intermediates in the nontraded sector. ${ }^{15}$ The production function for good $S$ assumed so far is therefore a special case of this more general formulation for $\mu_{s}=0$.

Formally, with Cobb-Douglas preferences the utility function in (1) is replaced by:

$$
U_{i}=(1-\alpha) \ln \frac{C_{i}(S)}{1-\alpha}+\alpha \ln \frac{C_{i}(M)}{\alpha}, \quad C_{i}(M)=\left(\int_{0}^{n} c_{i}(z)^{\frac{\sigma-1}{\sigma}} d z\right)^{\frac{\sigma}{\sigma-1}}
$$

where $\alpha \in(0,1)$ now represents the exogenous consumption expenditure share of manufacturing goods. Maximization of (19) yields:

$$
C_{i}(M)=\frac{\alpha\left(Y_{i}-T_{i} / L_{i}\right)}{P_{i}}, \quad C_{i}(S)=\frac{(1-\alpha)\left(Y_{i}-T_{i} / L_{i}\right)}{P_{i}(S)}
$$

where, as before, $Y_{i}-T_{i} / L_{i}$ is the expenditure per capita in country $i$ (with $T_{h}>0$ and $\left.T_{f}=-T_{h} /(N \epsilon)<0\right)$, and $Y_{i}$ is the labor efficiency of one worker. Using (20) in (19), and noting that $\ln P_{i}(S)=\mu_{s} \ln P_{i}$, yields a new expression for Home's indirect utility function:

$$
V_{h}=\ln \left(Y_{h}-T_{h} / L_{h}\right)-\left[\alpha+\mu_{s}(1-\alpha)\right] \ln P_{h} .
$$

Note also that expenditure on traded goods $E_{i}$ now comes from the Cobb-Douglas final demand in (20), and from the intermediate demand by the two sectors, i.e., $\mu p_{i} n_{i}+$ $\mu_{s} P_{i}(S) C_{i}(S)$. Thus, eqs. (15) are now replaced by the following expressions:

$$
\begin{aligned}
& E_{h}=\left[\alpha+\mu_{s}(1-\alpha)\right]\left(Y_{h} L_{h}-T_{h}\right)+\mu p_{h} n_{h}, \\
& E_{f}=\left[\alpha+\mu_{s}(1-\alpha)\right]\left(Y_{f} L_{f}+T_{i} /(N \epsilon)\right)+\mu p_{f} n_{f} .
\end{aligned}
$$

Otherwise, the model is unchanged. Thus, using (22) and (14) in (16), (17), and (18) yields a system of 5 equations in $P_{h}, P_{f}, E_{h}, E_{f}$ and $\epsilon$ that can be easily solved numerically.

By (21), the change in Home welfare after a transfer $T_{h}$ is

$$
\Delta V_{h}=\ln \left(1-\frac{T_{h}}{Y_{h} L_{h}}\right)+\left[\alpha+\mu_{s}(1-\alpha)\right] \ln \frac{P_{h, 0}}{P_{h, T}},
$$

where $P_{h, 0}$ and $P_{h, T}$ are the Home price indexes of manufacturing goods with $T_{h}=0$ and $T_{h}>0$, respectively, and

$$
\Delta \widetilde{V}_{h}=\ln \left(1-\frac{T_{h}}{Y_{h} L_{h}}\right)
$$

\footnotetext{
${ }^{15}$ Note that this formulation implies that now manufacturing goods enter the production function for traded and nontraded goods and the utility function through the same CES aggregator.
} 


\begin{tabular}{|c|c|c|c|c|c|c|c|c|}
\hline & \multicolumn{4}{|c|}{$\alpha=0.31$} & \multicolumn{4}{|c|}{$\alpha=0.12$} \\
\hline & \multicolumn{2}{|c|}{$\sigma=5$} & \multicolumn{2}{|c|}{$\sigma=3$} & \multicolumn{2}{|c|}{$\sigma=5$} & \multicolumn{2}{|c|}{$\sigma=3$} \\
\hline & $\tau=1.7$ & $\tau=2.7$ & $\tau=1.7$ & $\tau=2.7$ & $\tau=1.7$ & $\tau=2.7$ & $\tau=1.7$ & $\tau=2.7$ \\
\hline & (1) & $(2)$ & (3) & $(4)$ & $(5)$ & $(6)$ & (7) & $(8)$ \\
\hline$\overline{T_{R}}$ & 0.770 & 0.689 & 0.677 & 0.391 & 0.679 & 0.561 & 0.560 & 0.164 \\
\hline$\Delta \% \epsilon$ & -0.31 & 6.11 & -1.47 & -1.97 & -1.89 & 10.05 & -4.70 & -7.12 \\
\hline$\Delta \% n_{h}$ & 4.52 & 4.77 & 4.81 & 5.71 & 12.44 & 13.27 & 13.29 & 16.14 \\
\hline$\Delta \% n_{f}$ & -2.24 & -2.15 & -2.41 & -2.83 & -6.16 & -5.59 & -6.80 & -8.16 \\
\hline
\end{tabular}

Table 3: Numerical Simulations: China, Robustness

is the hypothetical welfare change at constant prices. Thus, the real cost of the transfer relative to a model with no price index effect is now

$$
T_{R} \equiv \frac{\Delta V_{h}}{\Delta \widetilde{V}_{h}}=\frac{\Delta V_{h}}{\ln \left(1-\frac{T_{h}}{Y_{h} L_{h}}\right)} .
$$

As in the previous Section, we simulate the model under two scenarios that broadly correspond to the observed surpluses of China and Germany, using the same baseline parameters values. Regarding the cost share of manufacturing intermediates in the nontraded sector, we set $\mu_{s}=0.05$, consistent with the US input-output tables. ${ }^{16}$ As for the share of manufacturing goods in consumption expenditure, using the manufacturing share of GDP as a proxy we obtain an $\alpha$ equal to 0.12 in the US and 0.31 in China. We therefore simulate the model with $\alpha=0.12$ and $\alpha=0.31$ to have a sense of how the results change when considering the plausible range of values for this parameter. The results are reported in Table 3. When considering the case of Germany trading with the rest of Europe, we instead set $\alpha=0.16$, which corresponds to the average EU manufacturing share of GDP. The latter results are reported in Table 4.

Comparing the new simulations in Table 3 to those in Table 1, we see that the beneficial price index effect is now weaker but still significant, with $T_{R}$ ranging from 0.77 to 0.16 . The average across simulations implies that the price effect can lower the real cost of the transfer to $56 \%$ of its value. Moreover, we confirm the previous finding that, excluding the case $\sigma=5$ and $\tau=2.7$, the transfer leads to a rise in the Home relative wage, and the appreciation is of the same order of magnitude as before. Finally, in all cases, the transfer still triggers a large relocation of firms from Foreign to Home and the size of the phenomenon is similar to the previous simulations. Comparing Tables 2 and 4 , for the case of Germany and the EU, we obtain similar conclusions. Although somewhat weaker in

\footnotetext{
${ }^{16}$ Results are not very sensitive to this parameter.
} 


\begin{tabular}{lcccc}
\hline \hline & \multicolumn{4}{c}{$\alpha=0.16$} \\
\cline { 2 - 5 } & \multicolumn{2}{c}{$\sigma=5$} & \multicolumn{2}{c}{$\sigma=3$} \\
& $(1)$ & $(2)$ & $(3)$ & $(4)$ \\
\hline$T_{R}$ & 0.785 & 0.646 & 0.761 & 0.475 \\
$\Delta \% \epsilon$ & -2.94 & 0.83 & -3.87 & -9.12 \\
$\Delta \% n_{h}$ & 18.39 & 20.11 & 18.68 & 22.24 \\
$\Delta \% n_{f}$ & -6.82 & -10.02 & -6.57 & -13.27 \\
\hline \hline Note: $T_{h}=4 \%$ of GDP, $L_{h}=1, L_{f}=0.2, N=27$ \\
$Y_{h}=6, Y_{f}=0.75 * Y_{h}, \mu=0.51, \mu_{s}=0.05$.
\end{tabular}

Table 4: Numerical Simulations: Germany, Robustness

magnitude, the price effect still lowers the real cost of the transfer significantly. Moreover, the effect on industrial location is still very large: a $4 \%$ surplus increases the number of manufacturing firms in Germany by about $20 \%$ and lowers it in the rest of the countries by around $10 \% .^{17}$

\section{Imbalances and Agglomeration}

So far, following the transfer's controversy, we have treated the transfer $T_{h}$ as exogenous and the exchange rate $\epsilon$ as endogenous. That is, we have implicitly assumed that the transfer is determined outside the model, either by the saving decision of agents as in the intertemporal approach to the current account (see e.g., Obstfeld and Rogoff, 1995); or by the active intervention of a government, for example by imposing capital controls and accumulating reserves (e.g., Benigno and Fornaro, 2012). We have then studied the implications of the transfer on prices, including the exchange rate, and welfare.

Although this is a scenario that has received significant attention in the literature, it is not the only relevant case. Rather than choosing $T_{h}$, a government could equally choose a value for $\epsilon$, and adjust actively the transfer in order to reach its target. For example, the Chinese government might have been intervening in the international capital markets so as to avoid any deterioration of the country's competitiveness. Alternatively, the model with a fixed $\epsilon$ may also describe the short-run equilibrium of economies with a fixed exchange rate and nominal rigidities (as, for instance, in Dornbusch, 1987).

Since the general equilibrium relationship between $T_{h}$ and $\epsilon$ is dictated by a tradeimbalance condition, one may expect that treating $T_{h}$ or $\epsilon$ as exogenous should not affect the results. This is indeed the case in our baseline model without intermediate goods. Interestingly, however, this is not necessarily true in the presence of intermediate goods,

${ }^{17}$ Consistently, the manufacturing share of GDP in Germany is about 30\% higher than the EU average. 
as the latter give rise to agglomeration economies and the possibility of multiple equilibria (see, e.g., Fujita et al. 1999). As a consequence, fixing $T_{h}$ or fixing $\epsilon$ may make a difference for the results. This is because fixing the size of the transfer is also equivalent to preventing agglomeration forces from fully deploying the circular and cumulative causation processes that lead to agglomeration. In contrast, fixing the exchange rate (or relative wages) can unleash agglomeration forces, because it prevents offsetting relative price changes.

To make our point, we use the model with intermediate goods to perform a different thought experiment than in the previous Section: rather than asking what happens when the government increases the transfer, we ask what happens when the government can fix the exchange rate or the size of the transfer. To obtain analytical results and simplify the comparison with Krugman and Venables (1995) and Fujita et al. (1999), we focus on a symmetric two-country version of our model. We then consider two scenarios: in the first the transfer is exogenously fixed at $T_{h}=0$; in the second, the exchange rate is exogenously fixed at the balanced-trade level $\epsilon=1$. Symmetry of course implies that in both cases a symmetric equilibrium always exists. The key question is therefore whether the symmetric equilibrium is also stable and whether there are other stable equilibria with agglomeration. The main result of this Section will be precisely to show that intervening in capital markets so as to keep relative wages fixed or adopting a fixed exchange rate in the presence of nominal rigidities may generate instability (at least in the short run, in the case of nominal rigidities): it can turn the symmetric equilibrium unstable, leading to agglomeration of manufacturing in the country that starts to run a trade surplus.

To study the stability properties of the symmetric equilibrium, we closely follow Krugman and Venables (1995) and Fujita et al. (1999). Specifically, we denote by $w_{i}$ the maximum wage (in local currency) that a manufacturing firm can pay and break even and we study how it varies out of equilibrium as a function of manufacturing employment, denoted by $\lambda_{i}$. Recall that, as in the previous Section, the wage paid by the nontraded sector in each country is the numeraire and $\epsilon$ is the exchange rate between the two numeraires. In equilibrium, $w_{i}=1$ in both countries under our assumption that the nontraded good is always produced in both countries. Yet, if we perturb the equilibrium by moving some firms from one country to the other, i.e., by changing $\lambda_{i}$, then $w_{i}$ will change as well. Then, the relationship between $w_{i}$ and $\lambda_{i}$ can be used to study the stability of the symmetric equilibrium. If this relationship is negative, it means that an expansion of the manufacturing sector requires firms to pay a wage below the wage paid by the nontraded sector. That is, firms are losing profitability and hence the equilibrium is stable. Conversely, a positive relationship between $w_{i}$ and $\lambda_{i}$ implies that agglomeration (an increase in $\lambda_{i}$ ) allows firms to pay higher wages and hence attract workers from the nontraded sector. In 
this case, firm profitability increases with the size of the manufacturing sector and hence the equilibrium is unstable.

Formally, (13) implies that the manufacturing wage bill is a constant share of revenue, i.e., $w_{i} \lambda_{i}=(1-\mu) n_{i} p_{i}$. This allows us to express the mass of manufacturing firms and manufacturing revenue in terms of manufacturing wages and employment:

$$
n_{i}=\frac{w_{i} \lambda_{i}}{p_{i}(1-\mu)} \Rightarrow \frac{n_{h} p_{h}}{n_{f} p_{f}}=\frac{w_{h} \lambda_{h}}{w_{f} \lambda_{f}}
$$

Next, recall that total expenditure on manufacturing goods equals $E_{i}=1+\mu n_{i} p_{i}$, which can we rewritten using (23) as

$$
E_{i}=1+\frac{\mu}{1-\mu} w_{i} \lambda_{i}
$$

The remaining equilibrium conditions needed to track the relationship between $w_{i}$ and $\lambda_{i}$ are, first, the expression for the price index:

$$
P_{h}^{1-\sigma}(1-\mu)=\lambda_{h} w_{h}^{1-\sigma(1-\mu)} P_{h}^{-\sigma \mu}+\phi \epsilon^{1-\sigma} \lambda_{f} w_{f}^{1-\sigma(1-\mu)} P_{f}^{-\sigma \mu},
$$

in which $n_{i}$ and $p_{i}$ have been substituted out; and, second, the market clearing condition for a firm:

$$
1=q_{h}=\left(w_{h}^{1-\mu} P_{h}^{\mu}\right)^{-\sigma}\left[P_{h}^{\sigma-1} E_{h}+\phi \epsilon^{\sigma} P_{f}^{\sigma-1} E_{f}\right] .
$$

Given $\epsilon$ and $\lambda_{i}$, these equations can be solved for $P_{i}, E_{i}$ and $w_{h}$.

We are now in the position to study the stability property of the equilibrium. As a preliminary step, we verify that when $T_{h}=0$ and $\epsilon$ adjusts endogenously, as in the previous Section, the (unique) equilibrium is always stable. To show this, note that Home expenditure on traded goods is equal to domestic sales plus imports:

$$
E_{h}=n_{h} p_{h} d_{h}+\epsilon n_{f} p_{f} x_{f} \tau .
$$

Since trade is balanced, the volume of imports is equal to the volume of export: $\epsilon n_{f} p_{f} x_{f}=$ $n_{h} p_{h} x_{h}$. Hence,

$$
E_{h}=n_{h} p_{h} d_{h}+n_{h} p_{h} x_{h} \tau
$$

But this is equal to the revenue of the traded sector in Home (domestic sales plus export): $E_{h}=n_{h} p_{h}$. Then, using (23), we get:

$$
\frac{w_{h} \lambda_{h}}{w_{f} \lambda_{f}}=\frac{E_{h}}{E_{f}} .
$$


Finally, substituting (24) yields $w_{h}=w_{f} \lambda_{f} / \lambda_{h}$. If Foreign is in equilibrium, $w_{f}=1$, then the relationship between $\lambda_{h}$ and $w_{h}$ is negative. Hence:

Proposition 4 Assume that $\sigma(1-\mu)>1$ and $N=L_{h}=L_{f}=1$. Then, under $T_{h}=0$, the unique symmetric equilibrium is stable:

$$
\frac{d w_{h}}{d \lambda_{h}}<0
$$

Starting at the symmetric equilibrium, in which $w_{h}=w_{f}=1$, a reallocation of manufacturing workers from Foreign to Home reduces the Home manufacturing wage below the wage paid by the nontraded sector, thereby implying that the symmetric equilibrium is globally stable. Thus, unlike in the standard new economic geography literature (see, e.g., Fujita et al., 1999) in our model agglomeration is impossible when $T_{h}$ is fixed. The intuition for this result is simple: independent of how strong agglomeration forces are, any incipient competitive advantage induced by the operation of agglomeration forces is offset by an appreciation of the exchange rate.

Suppose now that the exchange rate is fixed at $\epsilon=1$, i.e., at the symmetric equilibrium, and that the trade surplus $T_{h}$ adjusts according to (18). In this case, we obtain a system of equations almost identical to that studied in Krugman and Venables (1995). ${ }^{18}$ As in that paper, by linearizing the system of equations in the symmetric equilibrium we can obtain an analytical expression for $d w_{h} / d \lambda_{h}$. This yields the following Proposition (proof in the Appendix):

Proposition 5 Assume that $\sigma(1-\mu)>1$ and $N=L_{h}=L_{f}=1$. Assume also that $\epsilon=1$. Then, in a neighborhood of $T_{i}=0$,

$$
\frac{d w_{h}}{d \lambda_{h}}>0 \quad \text { iff } \quad \tau^{\sigma-1}<\frac{(1+\mu)(\sigma+\sigma \mu-1)}{(1-\mu)(\sigma-\sigma \mu-1)} .
$$

The condition in Proposition 5, which is identical to the one found in Krugman and Venables (1995), shows that the symmetric equilibrium can become unstable if $\mu$ is high and $\sigma$ and $\tau$ low. ${ }^{19}$ Figure 3 shows the critical level of trade costs below which the symmetric equilibrium is unstable as a function of $\mu$ for $\sigma=3$ and $\sigma=5$. When the symmetric equilibrium becomes unstable, manufacturing firms start to agglomerate in one

\footnotetext{
${ }^{18}$ The only marginal difference is quasi-linear instead of Cobb-Douglas utility.

${ }^{19}$ Note also that the point of symmetry breaking according to Proposition 5 is the same as the point in which a trade surplus leads to an appreciation of the exchange rate according to Proposition 3 . This is not by accident: when $\epsilon$ is exogenous, agglomeration forces make the symmetric equilibrium unstable, as in Krugman and Venables (1995). When $T$ is exogenous, instead, the symmetric equilibrium is always stable, and agglomeration forces show up in an appreciation of the exchange rate.
} 


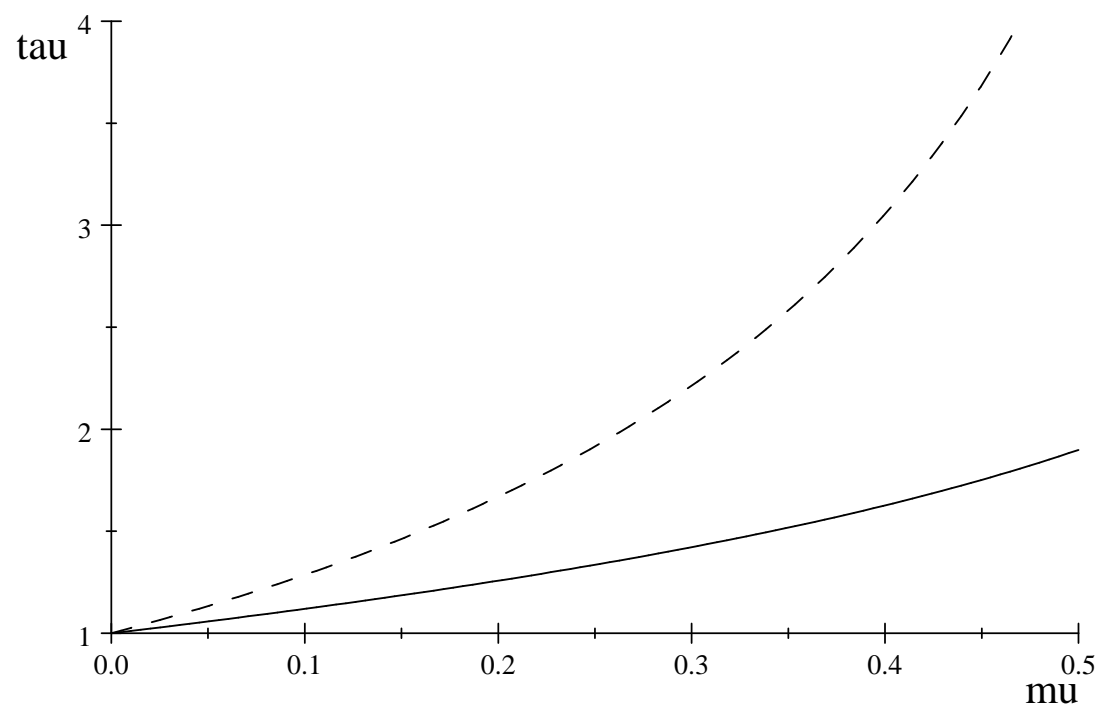

Figure 3: Trade Costs and Agglomeration. Critical values of $\tau$ below which the symmetric equilibrium becomes unstable, as a function of intermediate intensity. Solid line: $\sigma=5$; Dasehd line, $\sigma=3$.

country and that country runs a trade surplus. Interestingly, the condition in Proposition 5 is the same as the condition needed for the transfer to trigger an appreciation in Home, an outcome that appeared to be quite likley in our previous simulations.

Finally, our analysis suggests a possible reinterpretation of the key results in the new economic geography literature. According to this literature, agglomeration is triggered by a change in the structural parameters, such as a reduction in trade $\operatorname{costs} \tau$ or an increase in the importance of intermediate goods $\mu$ in manufacturing production. Yet, as shown in the previous Section, in our model agglomeration is impossible under balanced trade, whatever the parameter values. Our model suggests instead that trade imbalances might be a key driver of agglomeration, provided, of course, that the structural parameters are favorable to agglomeration. In other words, a country or region can become the "world factory" if able and willing to make a large transfer to its trading partners.

\section{Conclusion}

In this paper we have studied the welfare effects of trade imbalances, treated as an income transfer, in the Dixit-Stiglitz-Krugman model of monopolistic competition. This model is the workhorse of trade economists, and most recent developments in the trade theory build on it. It is therefore surprising that trade imbalances have received little attention in this setup. The main goal of this paper was to fill this gap, and in doing so we found 
new results that stand in sharp contrast with the conventional wisdom.

We have shown that trade imbalances have a large impact on the international location of manufacturing firms. A transfer increases the demand for nontraded goods for the recipient and lowers it for the donor. Hence, manufacturing firms move from the deficit to the surplus country. In the presence of trade costs, the relocation of production reduces the price index for the donor and raises it for the recipient. This price index effect is beneficial for consumers in the surplus country and, in the presence of intermediate goods, it also increases the competitiveness of manufacturing firms. If wages do not adjust, this mechanism generates a force towards agglomeration of manufacturing in the surplus country.

Realistic calibrations suggest that the price index effect can lower significantly the cost of the transfer. The exact magnitude of the effect depends crucially on parameters that are difficult to measure empirically, like the elasticity of substitution between varieties and trade costs. In all the cases, however, we find that a surplus is associated with a sharp increase in the size of the manufacturing sector.

Although derived in a relatively stylized model, these results can help explain several puzzling observations. For instance, the price-index effect can help rationalize why policy makers are often so worried about the decline in manufacturing employment. Our model is also consistent with the observation that developing countries experiencing a productivity take-off in their tradeable sectors tend to accumulate foreign assets, i.e., the so called "allocation puzzle" (Gourinchas and Jeanne, 2013). However, it would point to causality running from foreign asset accumulation to productivity growth. ${ }^{20} \mathrm{~A}$ careful empirical investigation of these mechanisms is still missing and seems an important challenge for future research in international finance and trade.

\section{Appendix}

\subsection{Proof of Proposition 3}

Note first that, when $N=L_{h}=L_{f}=1$, the model in Section 3 boils down to the following equations:

\footnotetext{
${ }^{20}$ Benigno and Fornaro (2012) put forward a similar hypothesis assuming a knowledge externality in the tradeable sector. Also, Rodrik (2008) finds that real exchange rate depreciations stimulate growth in developing countries and that this effect is increasing in the size of the tradeable sector. Our model provides a microfoundation for these effects.
} 


$$
\begin{aligned}
E_{i} & =1+\mu P_{i}^{\mu} n_{i}, \\
P_{h}^{\sigma-1} & =\frac{P_{h}^{\mu \sigma}-\phi \epsilon^{\sigma} P_{f}^{\mu \sigma}}{E_{h}\left(1-\phi^{2}\right)}, \quad P_{f}^{\sigma-1}=\frac{P_{f}^{\mu \sigma}-\phi \epsilon^{-\sigma} P_{h}^{\mu \sigma}}{E_{f}\left(1-\phi^{2}\right)}, \\
n_{h} & =P_{h}^{\mu(\sigma-1)}\left(\frac{E_{h}}{P_{h}^{\mu \sigma}-\phi \epsilon^{\sigma} P_{f}^{\mu \sigma}}-\frac{E_{f} \phi \epsilon}{\epsilon^{\sigma} P_{f}^{\mu \sigma}-\phi P_{h}^{\mu \sigma}}\right), \\
n_{f} & =P_{f}^{\mu(\sigma-1)}\left(\frac{E_{f}}{P_{f}^{\mu \sigma}-\phi \epsilon^{-\sigma} P_{h}^{\mu \sigma}}-\frac{\phi \epsilon^{-1} E_{h}}{\epsilon^{-\sigma} P_{h}^{\mu \sigma}-\phi P_{f}^{\mu \sigma}}\right), \\
T_{h} & =\phi\left(\frac{P_{f}^{\mu \sigma} \epsilon^{\sigma} E_{h}}{P_{h}^{\mu \sigma}-\phi \epsilon^{\sigma} P_{f}^{\mu \sigma}}-\frac{P_{h}^{\mu \sigma} \epsilon E_{f}}{\epsilon^{\sigma} P_{f}^{\mu \sigma}-\phi P_{h}^{\mu \sigma}}\right) .
\end{aligned}
$$

To study the comparative-statics effects of a small transfer and prove the results in Proposition 3 , we linearize the above system in the neighborhood of the symmetric balancedtrade point, i.e., we totally differentiate (27)-(31) with respect to $T_{h}$ in $T_{h}=0$. We define $\widehat{y} \equiv y^{\prime} / y$, where $y^{\prime} \equiv d y /\left.d T_{h}\right|_{T_{h}=0}$ is the total derivative of a variable in $T_{h}=0$. Moreover, we exploit country symmetry, which implies that $\widehat{y}_{f}=-\widehat{y}_{h}$.

In the symmetric balanced-trade equilibrium: $\epsilon=1, n_{h}=n_{f}=n, E_{h}=E_{f}=E$ and $P_{h}=P_{f}=P$. Using these in (27)-(29) we obtain:

$$
n=E P^{-\mu}, E=\frac{1}{1-\mu}, P^{\sigma(1-\mu)-1}=\frac{1-\mu}{1+\phi} .
$$

Totally differentiating (27) and using (32) yields:

$$
\widehat{E}_{h}=\mu^{2} \widehat{P}_{h}+\mu \widehat{n}_{h}
$$

Totally differentiating (28), using (32) and $\widehat{P}_{f}=-\widehat{P}_{h}$, yields:

$$
\begin{aligned}
(\sigma-1) \widehat{P}_{h} & =\frac{\mu \sigma \widehat{P}_{h}-\phi\left(\sigma \widehat{\epsilon}+\mu \sigma \widehat{P}_{f}\right)}{1-\phi}-\widehat{E}_{h} \\
& \Rightarrow \widehat{P}_{h}=-\frac{\phi \sigma \widehat{\epsilon}+(1-\phi) \widehat{E}_{h}}{(\sigma-1)(1-\phi)-\mu \sigma(1+\phi)}
\end{aligned}
$$

Similarly, totally differentiating (29), using (32) and exploiting country symmetry yields:

$$
\widehat{n}_{h}=\frac{1+\phi}{1-\phi} \widehat{E}_{h}+\frac{\phi}{1-\phi}\left(\frac{2 \sigma}{1-\phi}-1\right) \widehat{\epsilon}-\mu\left[\frac{4 \phi \sigma}{(1-\phi)^{2}}+1\right] \widehat{P}_{h} .
$$


Finanly, totally differentiating (31), using (32) and again exploiting symmetry yields:

$$
\left(\frac{2 \sigma}{1-\phi}-1\right) \widehat{\epsilon}=\frac{(1-\phi)(1-\mu)}{\phi}+\frac{4 \mu \sigma}{1-\phi} \widehat{P}_{h}-2 \widehat{E}_{h}
$$

Next, using (35) to eliminate $\widehat{n}_{h}$ from (33) yields:

$$
\begin{aligned}
\widehat{E}_{h} & =\mu^{2} \widehat{P}_{h}+\frac{1+\phi}{1-\phi} \mu \widehat{E}_{h}+\frac{\phi}{1-\phi} \mu\left(\frac{2 \sigma}{1-\phi}-1\right) \widehat{\epsilon}-\mu^{2}\left[\frac{4 \phi \sigma}{(1-\phi)^{2}}+1\right] \widehat{P}_{h} \\
& \Rightarrow \widehat{E}_{h}=\frac{\phi \mu(2 \sigma-1+\phi) \widehat{\epsilon}-4 \phi \sigma \mu^{2} \widehat{P}_{h}}{(1-\phi)[1-\phi-\mu(1+\phi)]}
\end{aligned}
$$

Using (37) to eliminate $\widehat{E}_{h}$ from (36) and (34) yields:

$$
\begin{aligned}
\widehat{\epsilon} & =\frac{1-\phi}{\phi} \frac{1-\phi-\mu(1+\phi)}{2 \sigma-1+\phi}+\frac{4 \sigma \mu}{2 \sigma-1+\phi} \widehat{P}_{h}, \\
\widehat{P}_{h} & =-\frac{\mu(1-\phi)+\sigma \phi \widehat{\epsilon}}{(\sigma-1)(1-\phi)-\mu \sigma(1+\phi)} .
\end{aligned}
$$

Solving for $\widehat{P}_{h}$ and $\widehat{\epsilon}$ we finally obtain:

$$
\begin{aligned}
\widehat{P}_{h} & =-\frac{(1-\phi)[\sigma+\mu(\sigma-1)]}{2 \sigma[\sigma(1-\mu)-1]+\mu \sigma(1+\phi)-(\sigma-1)(1-\phi)} \\
\widehat{\epsilon} & =\frac{(1-\phi)^{2}[\phi(1+\mu)(\sigma+\mu \sigma-1)-(1-\mu)(\sigma-\mu \sigma-1)]}{\phi\left\{(2 \sigma-1+\phi)[(\sigma-1)(1-\phi)-\mu \sigma(1+\phi)]+4 \phi \sigma^{2} \mu\right\}}
\end{aligned}
$$

Note that $\widehat{P}_{h}<0$ for $\sigma(1-\mu)>1 \Leftrightarrow \mu<\frac{\sigma-1}{\sigma}$. Note also that $\widehat{\epsilon}=\frac{1-\phi}{\phi} \frac{1-\phi}{2 \sigma-1+\phi}>0$ for $\mu=0$ and $\lim _{\mu \rightarrow \frac{\sigma-1}{\sigma}} \widehat{\epsilon}=-\frac{1-\phi}{\phi} \frac{2 \sigma-1}{\sigma}<0$. Hence the sign of $\widehat{\epsilon}$ switches from positive to negative in the relevant range of $\mu$. In particular, recalling that $\phi=\tau^{1-\sigma}$, we have that

$\widehat{\epsilon}<0$ iff $\mu>\frac{(2 \sigma-1)(1+\phi)-\sqrt{(1+\phi)^{2}+16 \sigma \phi(\sigma-1)}}{2 \sigma(1-\phi)} \Leftrightarrow \tau^{\sigma-1}<\frac{(1+\mu)(\sigma+\sigma \mu-1)}{(1-\mu)(\sigma-\sigma \mu-1)}$.

\subsection{Proof of Proposition 5}

To prove the results in Proposition 5, we totally differentiate equations (24)-(26) with respect to $T_{h}$ in $T_{h}=0$ under the assumption that the exchange rate is exogenously fixed at $\epsilon=1$. Moreover, as in the previous Appendix, we define $\widehat{y} \equiv y^{\prime} / y$, where $y^{\prime} \equiv d y /\left.d T_{h}\right|_{T_{h}=0}$ is the total derivative of a variable in $T_{h}=0$, and we exploit country symmetry, which implies that $\widehat{y}_{f}=-\widehat{y}_{h}$. 
Recall that in the symmetric balanced-trade equilibrium:

$$
\lambda_{h}=\lambda_{f}=w_{h}=w_{f}=1, E_{h}=E_{f}=\frac{1}{1-\mu} .
$$

Thus, totally differentiating (24) and using (41) yields:

$$
\widehat{E}_{h}=\mu\left(\widehat{w}_{h}+1\right) .
$$

Totally differentiating (25) and using (41) yields:

$$
\begin{aligned}
(1-\sigma) \widehat{P}_{h} & =\frac{1-\phi}{1+\phi}\left(1+[1-\sigma(1-\mu)] \widehat{w}_{h}-\sigma \mu \widehat{P}_{h}\right) \\
& \Rightarrow \widehat{P}_{h}=\frac{(1-\phi)[\sigma(1-\mu)-1] \widehat{w}_{h}-(1-\phi)}{(\sigma-1)(1+\phi)-(1-\phi) \sigma \mu}
\end{aligned}
$$

Totally differentiating (26) and using (41) yields:

$$
\begin{aligned}
(1-\mu) \sigma \widehat{w}_{h}+\mu \sigma \widehat{P}_{h} & =\frac{1-\phi}{1+\phi}\left[(\sigma-1) \widehat{P}_{h}+\widehat{E}_{h}\right] \\
& \Rightarrow \widehat{w}_{h}=\frac{[(1-\phi)(\sigma-1)-\mu \sigma(1+\phi)] \widehat{P}_{h}+(1-\phi) \widehat{E}_{h}}{(1-\mu)(1+\phi) \sigma} .
\end{aligned}
$$

Using (42) and (43) to eliminate $\widehat{E}_{h}$ and $\widehat{P}_{h}$ from $\widehat{w}_{h}$ finally yields:

$$
\widehat{w}_{h}=-\frac{\phi(1+\mu)(\sigma+\mu \sigma-1)-(1-\mu)(\sigma-\mu \sigma-1)}{(1-\phi)\left\{\left[\sigma(1-\mu) \frac{1+\phi}{1-\phi}-\mu\right]\left[(\sigma-1) \frac{1+\phi}{1-\phi}-\mu \sigma\right]-[\sigma(1-\mu)-1]\left(\sigma-1-\mu \sigma \frac{1+\phi}{1-\phi}\right)\right\}} .
$$

Note that the denominator of $\widehat{w}_{h}$ is greater than zero for $\sigma(1-\mu)>1$. Moreover, the numerator of $\widehat{w}_{h}$ is identical to the expression in square brackets on the numerator of $\widehat{\epsilon}$ in (39), which implies that $\widehat{w}_{h}>0$ whenever (40) holds, i.e., $\tau^{\sigma-1}<\frac{(1+\mu)(\sigma+\sigma \mu-1)}{(1-\mu)(\sigma-\sigma \mu-1)}$.

\section{REFERENCES}

[1] Anderson, James E. and Eric van Wincoop (2004). "Trade costs," Journal of Economic Literature 42, pp. 691-751.

[2] Bagwell, Kyle and Robert Staiger (2015). "Delocation and trade agreements in imperfectly competitive markets," Research in Economics 69(2), pp. 132-156.

[3] Benigno, Gianluca and Luca Fornaro (2012). "Reserve accumulation, growth and financial crises," Working Paper. 
[4] Bergin, Paul R. and Giancarlo Corsetti (2015). "Beyond competitive devaluations: The monetary dimension of comparative advantage," Working Paper.

[5] Bhagwati, Jagdish N., Richard A. Brecher and Tatsuo Hatta (1983). "The generalized theory of transfers and welfare: Bilateral transfers in a multilateral world," American Economic Review 73(4), pp. 606-18.

[6] Buera, Francisco J. and Joseph P. Kaboski (2012). "Scale and the origins of structural change," Journal of Economic Theory 147(2), pp. 684-712.

[7] Campolmi, Alessia, Harald Fadinger and Chiara Forlati (2013). "Trade policy: home market effect versus terms-of-trade externality," Journal of International Economics 93(1), pp. 92-107.

[8] Corsetti, Giancarlo, Philippe Martin and Paolo Pesenti (2013). "Varieties and the transfer problem," Journal of International Economics 89, pp. 1-12.

[9] Crinò, Rosario and Paolo Epifani (2014). "Trade imbalances, export structure and wage inequality," The Economic Journal 124, pp. 507-539.

[10] Davis, Donal R. (1998). "The home market, trade, and industrial structure," American Economic Review 88(5), pp. 1264-1276.

[11] Dixit, Avinash and Joseph Stiglitz (1977). "Monopolistic competition and optimum product diversity," American Economic Review 67(3), pp. 297-308.

[12] Dekle, Robert, Jonathan Eaton and Samuel Kortum (2007). "Unbalanced trade," American Economic Review PEPP 97(2), pp. 351-55.

[13] Dekle, Robert, Jonathan Eaton and Samuel Kortum (2008). "Global rebalancing with gravity: measuring the burden of adjustment," IMF Staff Papers 55(3), pp. 511-40.

[14] Dornbusch, Rudiger (1987), "Exchange rates and prices," American Economic Review 77, pp. 93-106.

[15] Dornbusch, Rudiger, Fischer, Stanley and Paul Samuelson (1977). "Comparative advantage, trade and payments in a Ricardian model with a continuum of goods," American Economic Review 67(5), pp. 823-39.

[16] Ethier, Wilfred (1982). "National and international returns to scale in the modern theory of international trade," American Economic Review 72, pp. 389-405.

[17] Fujita, Masahisa, Paul Krugman and Anthony Venables (1999). The Spatial Economy, MIT Press. 
[18] Melitz, Marc, and Fabio Ghironi (2005). "International trade and macroeconomic dynamics with heterogeneous firms," Quarterly Journal of Economics 120, pp. 865915.

[19] Gourinchas, Pierre-Olivier and Olivier Jeanne (2013). "Capital flows to developing countries: The allocation puzzle," Review of Economic Studies 80, pp. 1484-1515.

[20] Helpman, Elhanan (1998). "The size of regions," in D. Pines, E. Sadka and I. Zilcha, eds., Topics in Public Economics. Theoretical and Applied Analysis, Cambridge University Press, pp. 33-54.

[21] Helpman, Elhanan and Paul Krugman (1985). Market Structure and Foreign Trade, MIT Press.

[22] Krugman Paul (1980). "Scale economies, product differentiation and the pattern of trade," American Economic Review 70(5), pp. 950-959.

[23] Krugman, Paul and Anthony Venables (1995). "Globalization and the inequality of nations," Quarterly Journal of Economics 110, pp. 857-880.

[24] Melitz, Marc J, and Stephen J Redding (2014). "Heterogeneous firms and trade," in Handbook of International Economics, 4th ed., pp. 1-54.

[25] Melitz, Marc and Stephen Redding (2015). "New trade models, new welfare implications," American Economic Review 105(3), pp. 1105-46.

[26] Obstfeld, Maurice, and Kenneth Rogoff (1995). "The intertemporal approach to the current account," in Handbook of International Economics, 3rd ed., pp. 1731-99.

[27] Obstfeld, Maurice, Rogoff, Kenneth (2000). "The six major puzzles in international macroeconomics: Is there a common cause?" NBER Macroeconomics Annual, editors Ben S. Bernanke and Kenneth Rogoff, vol. 15, pp. 339-412.

[28] Obstfeld, Maurice, Rogoff, Kenneth (2007). "The unsustainable US current account position revisited," in R. Clarida, eds., G7 Current Account Imbalances: Sustainability and Adjustment, University of Chicago Press, Chicago, IL, pp. 339-376.

[29] Ossa, Ralph (2011). "A 'new trade' theory of GATT/WTO negotiations," Journal of Political Economy 119, pp. 122-152.

[30] Rodrik, Dani (2008) "The real exchange rate and economic growth," Brookings Papers on Economic Activity, pp. 365-412. 
[31] Samuelson, Paul (1954). "The transfer problem and transport costs: Analysis of effects of trade impediments," Economic Journal 64, pp. 264-289.

[32] Song, Zheng, Kjetil Storesletten, and Fabrizio Zilibotti (2011). "Growing like China," American Economic Review 101(1), pp. 196-233.

[33] Venables, Anthony (1987) "Trade and trade policy with differentiated products: A Chamberlinian-Ricardian model," The Economic Journal 97, pp. 700-717.

[34] Yamano, Norihiko and Nadmim Ahmad (2006). "The OECD input-output database, 2006 edition," OECD STI Working Paper 2006/8. 